\title{
Subgroup Characteristics of the Association between Volunteering and the Risk of Functional Disability Among Older Japanese People: The Tsurugaya Project.
}

\section{Teiichiro Yamazaki}

Division of Epidemiology, Department of Health Informatics and Public Health, Tohoku University School of Public Health, Graduate School of Medicine

Yumi Sugawara ( $\square$ yumi1717@med.tohoku.ac.jp )

Division of Epidemiology, Department of Health Informatics and Public Health, Tohoku University School of Public Health, Graduate School of Medicine

\section{Toshimasa Sone}

Division of Epidemiology, Department of Health Informatics and Public Health, Tohoku University School of Public Health, Graduate School of Medicine Ichiro Tsuji

Division of Epidemiology, Department of Health Informatics and Public Health, Tohoku University School of Public Health, Graduate School of Medicine

\section{Research Article}

Keywords: volunteering , incident functional disability, socio-demographic factors, Cox proportional hazard model

Posted Date: December 21st, 2020

DOI: https://doi.org/10.21203/rs.3.rs-129031/v1

License: (1) This work is licensed under a Creative Commons Attribution 4.0 International License. Read Full License

Version of Record: A version of this preprint was published at Archives of Gerontology and Geriatrics on September 1st, 2021. See the published version at https://doi.org/10.1016/j.archger.2021.104465. 


\section{Abstract}

This prospective cohort study aimed to identify the subgroups of older people in which the association between volunteering and incident functional disability is most remarkable by conducting subgroup analyses of age, sex, chronic medical condition, and socio-demographic factors. Participants were 826 Japanese community-dwelling people aged $\geq 70$ years who lived in Tsurugaya, Sendai. Volunteering status was assessed with a baseline survey conducted in 2003. Incident functional disability was defined as the first certification of Long-term Care Insurance until 2017. The Cox proportional hazard model was used to estimate the multivariate-adjusted hazard ratios (HR) with $95 \%$ confidence intervals (Cl) for incident functional disability. Subgroup analyses were conducted according to sex, age, medical history, marital status, and educational level. The risk of incident functional disability was significantly lower in current volunteers (HR 0.70, 95\% $\mathrm{Cl} 0.51-0.96)$ than non-volunteers. This significant association was remarkable in several subgroups such as women, those aged 75 years or over, those living with chronic illnesses, those living without a spouse, and participants with higher educational levels. The association between volunteering and a decreased risk of incident functional disability was remarkable among vulnerable groups such as women, old-old, those living with chronic illnesses, and those living without a spouse.

\section{Introduction}

As the proportion of Japanese people aged 65 years or over (especially 75 years or over) has been increasing, Japan's long-term care costs have been increasing ${ }^{1}$. Therefore, reducing the increase in longterm care costs by extending healthy life expectancy is an urgent issue. Social participation, such as work, hobby, sports, local community activities, or volunteering, and playing a social role through these activities are recommended on the assumption that they are related to purpose in life and long-term care prevention for older people in the Long-term Care Prevention and Assisting Daily Living Project (Kaigoyobou Nichijyouseikatushien Sougoujigyou) implemented by the Japanese Ministry of Health, Labor and Welfare ${ }^{2}$. In fact, previous studies consistently reported significant associations between work, hobbies, sports, or local community activities and incident functional disability among older people ${ }^{3-6}$. Likewise, many previous studies reported significant associations between volunteering and physical health, such as independence of activities of daily living (ADL), instrumental ADL (IADL), and physical disability ${ }^{7-11}$. However, several Japanese studies reported no associations between volunteering and incident functional disability 3,6 .

These results indicate that the association between volunteering and incident functional disability depends upon characteristics of older people. Several cohort studies investigated whether the association between volunteering and physical health varies by sex, educational level, and income level ${ }^{12-14}$. Regarding sex differences, several prospective cohort studies among older people were reported. Two Japanese studies reported that a significant association between volunteering and reduced risk of IADL decline was seen only in women and not men ${ }^{14,15}$. A U.S. study reported that only high-intensity 
volunteering improved physical function among men, but low- and high-intensity volunteering suppressed the progression of physical disability among women ${ }^{13}$.

We hypothesize that the strength of the association between volunteering and incident functional disability varies by subgroups of older people. Clarification of the characteristics of older people for whom volunteering markedly prevents long-term care and extends healthy life expectancy is essential. However, few studies investigated whether the association between volunteering and incident disability varies by subgroups of older people.

The present study aimed to identify the subgroups of older people in which the association between volunteering and decreased risk of incident functional disability is most remarkable. We conducted subgroup analyses of age, sex, chronic medical condition, and socio-demographic factors using a prospective cohort among Japanese community-dwelling people aged 70 years or over.

\section{Results}

\section{Characteristics of study participants.}

Of the 826 participants, 79 (9.5\%) were current volunteers, 22 (2.7\%) were former volunteers, and 725 (87.8\%) were non-volunteers (Table 1). Former volunteers were more likely than non-volunteers to be older, be unemployed, have moderate to severe physical pain, have limited physical function, have fewer depressive symptoms, have some hobby activities, and not be current drinkers. Current volunteers were more likely than non-volunteers to have less physical pain, have a higher physical function, have fewer depressive symptoms, have social support, have some hobby activities, and be current drinkers. 
Table 1

Baseline characteristics by volunteering status.

\begin{tabular}{|c|c|c|c|c|}
\hline & \multicolumn{3}{|c|}{ Volunteering status } & \multirow{3}{*}{$\begin{array}{l}P \\
\text { value }\end{array}$} \\
\hline & $\begin{array}{l}\text { Non- } \\
\text { volunteers }\end{array}$ & $\begin{array}{l}\text { Former } \\
\text { volunteers }\end{array}$ & \multirow{2}{*}{$\begin{array}{l}\text { Current } \\
\text { volunteers } \\
n=79\end{array}$} & \\
\hline & $n=725$ & $\mathrm{n}=22$ & & \\
\hline Age (years) (median, IQR) & $74(72-78)$ & $78(75-82)$ & $\begin{array}{l}73(71- \\
76)\end{array}$ & $<001$ \\
\hline Male, $\%$ & 46.3 & 54.5 & 59.5 & 0.07 \\
\hline Body mass index, $\%$ & & & & 0.38 \\
\hline$\leq 18.4 \mathrm{~kg} / \mathrm{m}^{2}$ & 5.2 & 9.1 & 2.5 & \\
\hline$\geq 25 \mathrm{~kg} / \mathrm{m}^{2}$ & 39.6 & 22.7 & 38.0 & \\
\hline Married, \% & 66.8 & 77.3 & 72.2 & 0.39 \\
\hline Lower educational level ( $\leq 17$ years), $\%$ & 34.2 & 36.4 & 24.1 & 0.57 \\
\hline Employed, \% & 13.5 & 0 & 2.5 & $<.001$ \\
\hline Presence of medical history, \% & 65.7 & 68.2 & 58.2 & 0.40 \\
\hline Stroke & 3.4 & 4.5 & 2.5 & 0.87 \\
\hline Myocardial infarction & 10.5 & 13.6 & 7.6 & 0.63 \\
\hline Cancer & 8.8 & 4.5 & 10.1 & 0.72 \\
\hline Diabetes & 15.3 & 13.6 & 13.9 & 0.93 \\
\hline Bronchial asthma & 6.1 & 4.5 & 3.8 & 0.69 \\
\hline Cataract & 38.3 & 36.4 & 26.6 & 0.12 \\
\hline Glaucoma & 8.4 & 13.6 & 2.5 & 0.11 \\
\hline Arthritis & 17.4 & 18.2 & 11.4 & 0.40 \\
\hline Serum albumin ( $\mathrm{g} / \mathrm{dL})$ (median, IQR) & $\begin{array}{l}4.2(4.0- \\
4.3)\end{array}$ & $4.2(4.0-4.3)$ & $\begin{array}{l}4.2(4.1- \\
4.3)\end{array}$ & 0.64 \\
\hline Moderate to severe physical pain, $\%$ & 16.7 & 31.8 & 6.3 & $<0.05$ \\
\hline Lower TUG performance ( $\geq 9.67 \mathrm{~s}), \%$ & 33.9 & 50.0 & 17.7 & $<0.05$ \\
\hline $\begin{array}{l}\text { Depressive symptoms (GDS score } \geq 11 \text { ), } \\
\%\end{array}$ & 26.5 & 9.1 & 13.9 & $<0.01$ \\
\hline Lower cognitive function (MMSE score $\leq$ & 25.5 & 27.3 & 15.2 & 0.15 \\
\hline
\end{tabular}




\begin{tabular}{|c|c|c|c|c|}
\hline Absence of social support, \% & 34.6 & 36.4 & 19.0 & $<0.05$ \\
\hline No hobby activities, $\%$ & 50.5 & 22.7 & 15.2 & $\hat{0}_{0.0001}$ \\
\hline Current smoker, \% & 10.3 & 13.6 & 10.1 & 0.39 \\
\hline Current drinker, $\%$ & 41.2 & 22.7 & 62.0 & $<001$ \\
\hline $\begin{array}{l}\text { Lower physical activity ( } \leq 34.3 \\
\text { METs/day), \% }\end{array}$ & 28.1 & 18.2 & 13.9 & 0.11 \\
\hline \multicolumn{5}{|c|}{$\begin{array}{l}{ }^{\dagger} \text { The } \chi^{2} \text {-test or Fisher's exact test was applied for categorical variables and Kruskal-Wallis test for } \\
\text { continuous variables including age and serum albumin. IQR, Interquartile Range; TUG, Timed Up and } \\
\text { Go test; GDS, Geriatric Depression Scale; MMSE, Mini-Mental State Examination; MET, Metabolic } \\
\text { equivalent. }\end{array}$} \\
\hline
\end{tabular}

\section{Association between volunteering and incident disability.}

We observed a total of 7076 person-years, and 532 participants (64.4\%) had an incident functional disability (Fig. 1). Table 2 shows the characteristics of participants according to the presence or absence of incident functional disability. Participants with incident functional disability were more likely to be older, be female, be unmarried, tend to have a medical history, and have a lower educational level (Table 2). Table 3 shows the relationship between volunteering and incident functional disability. After full adjustment for confounders (model 2), current volunteers were significantly associated with a $30 \%$ lower risk of incident functional disability compared to non-volunteers $(\mathrm{HR}=0.70 ; 95 \% \mathrm{Cl}, 0.51-0.96 ; \mathrm{P}=$ 0.027 ) (Table 3). By contrast, former volunteers showed no association with a risk of incident functional disability $(\mathrm{HR}=1.41 ; 95 \% \mathrm{Cl}, 0.85-2.34 ; \mathrm{P}=0.18)$. 
Table 2

Baseline characteristics by outcome status.

\begin{tabular}{|c|c|c|c|}
\hline & Incident $\mathrm{f}$ & al disability & $P$ value \\
\hline & Without & With & \\
\hline & $(n=294)$ & $(n=532)$ & \\
\hline Higher age ( $\geq 75$ years), \% & 26.5 & 57.3 & $<0.0001$ \\
\hline Male, $\%$ & 57.1 & 42.7 & $<0.0001$ \\
\hline Body mass index, $\%$ & & & 0.09 \\
\hline$\leq 18.4 \mathrm{~kg} / \mathrm{m}^{2}$ & 5.8 & 4.7 & \\
\hline$\geq 25 \mathrm{~kg} / \mathrm{m}^{2}$ & 34.0 & 41.7 & \\
\hline Married, \% & 75.9 & 63.1 & 0.0002 \\
\hline Lower educational level ( $\leq 17$ years), \% & 29.4 & 36.6 & 0.003 \\
\hline Employed, \% & 17.4 & 12.8 & 0.10 \\
\hline Presence of medical history, \% & 58.2 & 68.8 & 0.002 \\
\hline Moderate to severe bodily pain, $\%$ & 10.4 & 19.8 & $<0.0001$ \\
\hline Lower TUG performance ( $\geq 9.67 \mathrm{~s}), \%$ & 19.8 & 41.0 & $<0.0001$ \\
\hline Depressive symptoms (GDS score $\geq 11$ ), \% & 18.9 & 28.4 & 0.003 \\
\hline Lower cognitive function (MMSE score $\leq 27$ ), \% & 18.6 & 28.4 & 0.002 \\
\hline Absence of social support, \% & 30.4 & 38.2 & 0.03 \\
\hline No hobby activities, \% & 46.6 & 48.8 & 0.55 \\
\hline Current smoker, \% & 9.4 & 11.2 & 0.03 \\
\hline Current drinker, \% & 48.9 & 45.7 & 0.35 \\
\hline Lower physical activity ( $\leq 34.3$ METs/day), \% & 29.4 & 35.3 & 0.31 \\
\hline
\end{tabular}


Table 3

Association between volunteering and the risk of incident functional disability.

\begin{tabular}{|c|c|c|c|}
\hline & \multicolumn{3}{|c|}{ Volunteering status } \\
\hline & Non-volunteers & Former volunteers & Current volunteers \\
\hline & $\mathrm{n}=725$ & $\mathrm{n}=22$ & $\mathrm{n}=79$ \\
\hline Person-years & 6087 & 134 & 809 \\
\hline Incident functional disability, n (\%) & $470(64.8)$ & $17(77.2)$ & $45(57.0)$ \\
\hline Death, n (\%) & $73(10.1)$ & $1(4.5)$ & $4(5.1)$ \\
\hline HR (95\% Cl): Crude & 1.00 (reference) & $1.72(1.06-2.79)$ & $0.68(0.50-0.93)$ \\
\hline HR (95\% Cl): Model $1^{\dagger}$ & 1.00 (reference) & $1.33(0.82-2.17)$ & $0.72(0.53-0.98)$ \\
\hline HR (95\% Cl): Model $2^{\ddagger}$ & 1.00 (reference) & $1.41(0.85-2.34)$ & $0.70(0.51-0.96)$ \\
\hline \multicolumn{4}{|c|}{$\begin{array}{l}\text { ₹Adjusted for Model } 1+\text { marital status (living with a spouse, living without a spouse, missing), } \\
\text { education level (age upon graduation from last school } \leq 17,18-21, \geq 22 \text { years, missing), occupational } \\
\text { status (employed, not employed, missing), medical history (stroke, myocardial infarction, cancer, } \\
\text { diabetes, bronchial asthma, cataract, glaucoma, arthritis), physical pain (moderate to severe, very mild } \\
\text { to mild, none, missing), Timed up and go test (in } s \text { (men): } \leq 8.01,8.02-9.29, \geq 9.30 \text {, missing; in } s \\
\text { (women): } \leq 8.41,8.42-10.1, \geq 10.2 \text {, missing), depressive symptoms }(\leq 10,11 \geq \text { Geriatric Depression } \\
\text { Scale (GDS) score, missing), social support (presence, absence, missing), hobby activity status (none, } \\
\text { any, missing). }\end{array}$} \\
\hline
\end{tabular}

\section{Subgroup analyses for the characteristics of older people.}

We conducted subgroup analyses according to sex, age, medical history, marital status, and educational level. The proportion of current volunteers who were women, aged 75 years or over, with a medical history, unmarried, and with a lower educational level was lower than the proportion of men, those younger than 75 years, those without a medical history, those who were married, and those with a higher educational level (7-9\% vs. 10-12\%, respectively) (Fig. 2). A significant association between volunteering and disability risk was observed among women $(\mathrm{HR}=0.50 ; 95 \% \mathrm{Cl}, 0.29-0.86 ; \mathrm{P}=0.012)$ but not men, among those aged 75 years or over $(\mathrm{HR}=0.56 ; 95 \% \mathrm{Cl}, 0.35-0.88 ; \mathrm{P}=0.012)$ but not those younger than 75 years, among those with a medical history $(\mathrm{HR}=0.57 ; 95 \% \mathrm{Cl}, 0.37-0.87 ; \mathrm{P}=0.009)$ but not those without, among unmarried subjects $(\mathrm{HR}=0.40 ; 95 \% \mathrm{Cl}, 0.20-0.78 ; \mathrm{P}=0.007)$ but not married subjects, 
and among those with a higher educational level $(\mathrm{HR}=0.63 ; 95 \% \mathrm{Cl}, 0.42-0.94 ; \mathrm{P}=0.022)$ but not a lower educational level (Fig. 2).

\section{Discussion}

This prospective cohort study investigated the subgroups of older people in which the association between volunteering and decreased risk of incident functional disability was most remarkable by conducting subgroup analyses. The significant association between volunteering and a decreased risk of incident disability was remarkable in such subgroups as women, those aged 75 years or over, those with a medical history, unmarried subjects, and those with a higher educational level. Several cohort studies investigated whether the association between volunteering and physical health varies by sex ${ }^{13-15}$ or educational level ${ }^{12}$. Regarding sex, our finding of a significant association between volunteering and disability risk among women but not men was consistent with previous studies ${ }^{14,15}$. We found a significant association between volunteering and incident functional disability in only those with a higher educational level, whereas a previous Japanese study reported no associations regardless of educational level $^{12}$. No previous studies reported differences in the association between volunteering and physical health according to age, medical history, and marital status. Our results offer new evidence that a significant association between volunteering and incident functional disability was observed only in people aged 75 years or over, those with a medical history, and those who are unmarried.

The proportions of participants aged 75 years or over, women, unmarried participants, those with a medical history, and those with a lower educational level among participants with an incident functional disability were higher than those without these features in this study (Table 2). Thus, subgroups such as women, those aged 75 years or over, those with a medical history, and unmarried subjects were vulnerable to incident functional disability. Prior studies reported that older people's characteristics, such as female sex, old age, having a chronic illness, and living without a spouse, were associated with a risk of disability ${ }^{23-26}$. Our findings suggest that volunteering may reduce the risk of incident functional disability in vulnerable older people. However, the current proportion of volunteers in these vulnerable groups was lower than that in non-vulnerable groups (7-9\% vs. 10-12\%, respectively) (Fig. 2). Therefore, volunteering could be encouraged more for vulnerable older people as a way to prevent long-term care and prolong a healthy life expectancy.

The present study has several strengths. First, we performed face-to-face interviews and measured objective indices in all participants in the baseline survey. Second, the present study had a longer followup period (median 8.7 years) than previous studies (3-6 years) ${ }^{12,15}$; thus, the follow-up time in the present study was sufficient to observe the onset of incident functional disability. Third, we confirmed incident functional disability through the national LTCI system in Japan; hence, the follow-up rate and the precision of outcome measuring were high.

Despite these strengths, this study has some limitations. First, this study's participation rate was low; thus, self-selection bias that may result in a reduction in generalizability is a concern. However, 
volunteering was associated with a lower risk of incident functional disability, especially among the vulnerable groups in this study. Therefore, our findings suggest that volunteering is particularly applicable to vulnerable people. Second, the frequency and intensity of volunteering were not measured in this study. Previous studies reported that the association between volunteering and risk of incident functional disability varies by frequency of volunteering ${ }^{5,13}$; thus, further studies are needed that include assessment of the frequency and intensity of volunteering. Third, whether the volunteering status changed during the observational period is unknown in this study; thus, future studies require a research design that unifies changes in volunteering status, such as that described by Carr et $\mathrm{al}^{13}$. Fourth, confounders reported in previous studies, such as willingness to voluntee ${ }^{27}$ or income level ${ }^{12}$, were not measured, which could weaken the association observed in this study. Future studies need to consider these confounders.

\section{Conclusion}

We performed subgroup analyses using a prospective cohort to identify the subgroups of older people in which the association between volunteering and decreased risk of incident functional disability was most remarkable. Current volunteering was associated with a lower risk of incident functional disability, especially among vulnerable groups such as those living without a spouse, women, those aged 75 years or over, and those living with chronic illnesses.

\section{Methods}

\section{Study participants.}

This prospective cohort study was conducted as a part of the Tsurugaya project, which is a comprehensive geriatric assessment (CGA), and concepts, designs, and details of the project are described elsewhere ${ }^{16,17}$. We invited 2,925 community-dwelling people aged 70 years or over living in the Tsurugaya area of Sendai in northern Japan to participate in the project. Of those, 947 residents participated in the CGA held in July 2003. All participants provided written informed consent for us to obtain and use the CGA data, follow-up regarding death or moving out of the area, and national LongTerm Care Insurance (LTCI) certification status. We excluded 121 participants for the following reasons: disagreed with the present study $(n=41)$, already certified for LTCl at baseline $(n=75)$, and invalid volunteering status $(n=5)$. Finally, 826 participants were included in the final analysis (mean age, $75.2 \pm$ 4.5 years; male, 48\%) (Fig. 1). At the time of the CGA, we had explained to the participants that we would obtain and use the information of the CGA data, follow-up of death or moving out, and LTCl certification status, then we had written consent from them. The institutional review boards of the Tohoku University Graduate School of Medicine (Sendai, Japan) approved this study. This study was conducted following the Ethical Guidelines for Medical and Health Research Involving Human Subjects formulated by the Japanese Ministry of Health, Labor and Welfare.

\section{Outcome variable (incident functional disability).}


We defined incident functional disability as certification for the national LTCI system in Japan ${ }^{18}$. The LTCI certification consists of seven caregiving levels, from support level 1 and 2, to care level 1 to 5 . In this study, we defined a new certification more than support level 1 as incident functional disability. LTCI certification was correlated with the Barthel Index scores ${ }^{19}$. We received permission to conduct the study in the Tsurugaya area and obtained each participant's information regarding the date of the LTCI certification, the level of caregiving, death, and moving out of Sendai from the Sendai City government. The follow-up period was from July 2003 until June 2017. Participants who moved out from Sendai or who died were defined as censored.

\section{Exposure variable (volunteering status).}

The volunteering status was obtained from the questionnaire used in the CGA. The questions about volunteering status were as follows: "After retirement, A) I have been volunteering, or B) I had been volunteering." We classified the volunteering status into three groups. If participants chose $A$, we defined them as "current volunteers", and if they chose B, we defined them as "former volunteers". If participants chose neither, we defined them as "non-volunteers".

\section{Covariates.}

Information about covariates was also collected at the CGA. The participants were surveyed regarding sex, age, medical history, educational level, marital status, occupational status, physical pain, physical function, depressive symptoms, social support, and hobby activities.

Medical history was divided into two categories (presence or absence). If participants had a history of one or more diseases, such as stroke, myocardial infarction, cancer, diabetes, bronchial asthma, cataracts, glaucoma, or arthritis, we defined them as having the presence of a medical history. The educational level was classified into three categories (age at last graduation from school $\leq 17,18-21, \geq$ 22 years). Marital status was divided into two categories (married or unmarried). We defined participants who lived with a spouse as "married" and participants who lived without a spouse due to being single, divorced, widowed, and other reasons as "unmarried". Occupational status was divided into two categories (employed or not employed). Participants defined as "employed" included those who were selfemployed. Regarding physical pain, participants were asked, "How much pain did you experience within the last 4 weeks?," and based on the answers, we divided the participants into three categories (none, very mild to mild, moderate to severe). Physical function was measured using the Timed Up and Go test ${ }^{20}$. We classified the participants into tertile groups based on their time $(\leq 8.23,8.24-9.66, \geq 9.67 \mathrm{sec})$. Depressive symptoms were measured using the Japanese version of the 30 -item Geriatric Depression Scale ${ }^{21,22}$. Scores $\geq 11$ indicate depressive symptoms; thus, we classified the participants into two groups based on the score $(\leq 10, \geq 11)$. To assess social support, we asked participants the following five questions: "Do you have someone 1) with whom you can consult when you are in trouble? 2) with 
whom you can consult when your physical condition is poor? 3) who can help with your daily housework? 4) who can take you to a hospital when your physical condition is not good? 5) who can take care of you when you are ill in bed? For each question, participants chose yes or no. We defined participants who did not answer "yes" to all five questions as having an absence of social support. We classified hobby activities into two categories (any or none). If participants answered that they had any hobby activities such as cultural activities, exercises, or sports, we defined them as "any." For all covariates, missing information was modeled as dummy variables.

\section{Statistical analysis.}

We calculated person-years of follow-up from July 1 st, 2003 to the first endpoint, which is the date of incident functional disability, the date of death, the date of moving out of Sendai, or administrative censoring on June 30th, 2017. We used Kruskal-Wallis tests to compare the median of continuous variables (such as age) and $\chi^{2}$ tests or Fisher's exact tests to compare the categorical variables (such as sex) among the three volunteering statuses.

The Cox proportional hazard model was used to calculate hazard ratios (HRs) with $95 \%$ confidence intervals (Cls) for incident functional disability according to the volunteering status ("current volunteers," "former volunteers," or "non-volunteers"). We used the following two models to analyze the association between volunteering and incident functional disability. Model 1 was adjusted by sex and age, and Model 2 was further adjusted for marital status, educational level, occupational status, medical history, physical pain, physical function, depressive symptoms, social support, and hobby activities.

To identify the subgroups of older people in which the association between volunteering and a decreased risk of incident functional disability is most remarkable, we conducted subgroup analyses according to sex (male or female), age ( $\leq 74$ or $\geq 75$ years), medical history (presence or absence), marital status (married or unmarried), educational level (age upon graduation from the last school $\leq 17$ years [lower] or $\geq 18$ years [higher]). We used the multivariate adjusted model (Model 2) for the subgroup analyses.

P-values $<0.05$ were considered statistically significant, and all tests were two-sided. All statistical analyses were performed using SAS version 9.4 (SAS Institute Inc., Cary, NC, USA).

\section{Declarations}

\section{Data availability}

The datasets used and/or analyzed during the current study are available from the corresponding author on reasonable request.

\section{Funding}


This work was supported by Tohoku University Graduate School of Medicine.

\section{Author contributions}

T.Y., Y.S. and I.T. designed the research; Y.S., T.S. and I.T. conducted the research; T.Y. and Y.S. analyzed the data; T.Y. wrote the paper; Y.S., T.S., and I.T. gave constructive suggestions; T.Y. had primary responsibility for the final content. All authors read and approved the final manuscript.

\section{Competing interests}

The authors declare no competing interests.

Correspondence and requests for materials should be addressed to Y.S.

\section{References}

1. Cabinet Office. Annual Report on the Ageing Society: 2018 (Summary) - Cabinet Office Home Page. https://www8.cao.go.jp/kourei/english/annualreport/2018/2018pdf_e.html.

2. Ministry of Health, L. and W. Basic concept of long-term care prevention and assisting daily living project. [Kaigoyobou Nichijyouseikatushiensougoujigyou no kihontekina kangaekata]. https://www.mhlw.go.jp/file/06-Seisakujouhou-12300000-Roukenkyoku/0000192996.pdf (2015).

3. Kanamori, S. et al. Social participation and the prevention of functional disability in older Japanese: The JAGES cohort study. PLoS One 9, 1-10 (2014).

4. Hikichi, H. et al. Effect of a community intervention programme promoting social interactions on functional disability prevention for older adults: propensity score matching and instrumental variable analyses, JAGES Taketoyo study. J. Epidemiol. Community Health 69, 905-910 (2015).

5. Otsuka, T. et al. Association between social participation and incident risk of functional disability in elderly Japanese: The Ohsaki Cohort 2006. J. Psychosom. Res. 111, 36-41 (2018).

6. Ide, K. et al. Social Participation and Functional Decline: A Comparative Study of Rural and Urban Older People, Using Japan Gerontological Evaluation Study Longitudinal Data. Int. J. Environ. Res. Public Health 17, 1-13 (2020).

7. Morrow-Howell, N., Hinterlong, J., Rozario, P. A. \& Tang, F. Effects of Volunteering on the Well-Being of Older Adults. Journals Gerontol. - Ser. B Psychol. Sci. Soc. Sci. 58B, 137-145 (2003).

8. Menec, V. H. The Relation Between Everyday Activities and Successful Aging: A 6-Year Longitudinal Study. Soc. Sci. 58, 74-82 (2003).

9. Lum, T. Y. \& Lightfoot, E. The effects of volunteering on the physical and mental health of older people. Res. Aging 27, 31-55 (2005). 
10. Hong, S. I. \& Morrow-Howell, N. Health outcomes of Experience Corps $₫$ : A high-commitment volunteer program. Soc. Sci. Med. 71, 414-420 (2010).

11. Gonzales, E., Shen, H.-W., Perry, T. E. \& Wang, Y. Intersections of Home, Health, and Social Engagement in Old Age: Formal Volunteering as a Protective Factor to Health After Relocation. Res. Aging 016402751877312 (2018).

12. Ashida, T., Kondo, N. \& Kondo, K. Social participation and the onset of functional disability by socioeconomic status and activity type: The JAGES cohort study. Prev. Med. (Baltim). 89, 121-128 (2016).

13. Carr, D. C., Kail, B. L. \& Rowe, J. W. The Relation of Volunteering and Subsequent Changes in Physical Disability in Older Adults. Journals Gerontol. - Ser. B Psychol. Sci. Soc. Sci. 73, 511-521 (2018).

14. Tomioka, K., Kurumatani, N. \& Saeki, K. The differential effects of type and frequency of social participation on IADL declines of older people. PLoS One 13, 1-17 (2018).

15. Tomioka, K., Kurumatani, N. \& Hosoi, H. Association Between Social Participation and 3-Year Change in Instrumental Activities of Daily Living in Community-Dwelling Elderly Adults. J. Am. Geriatr. Soc. 65, 107-113 (2017).

16. Hozawa, A. et al. C-Reactive Protein and Peripheral Artery Disease among Japanese Elderly: the Tsurugaya Project. Hypertens. Res. 27, 955-961 (2004).

17. Kuriyama, S. et al. Green tea consumption and cognitive function: A cross-sectional study from the Tsurugaya Project. Am. J. Clin. Nutr. 83, 355-361 (2006).

18. Tsutsui, T. \& Muramatsu, N. Care-needs certification in the long-term care insurance system of Japan. J. Am. Geriatr. Soc. 53, 522-527 (2005).

19. Arai, Y., Zarit, S. H., Kumamoto, K. \& Takeda, A. Are there inequities in the assessment of dementia under Japan's LTC insurance system? Int. J. Geriatr. Psychiatry 18, 346-352 (2003).

20. Nordin, E., Rosendahl, E. \& Lundin-Olsson, L. Timed ‘Up \& Go' Test: Reliability in Older People Dependent in Activities of Daily Living-Focus on Cognitive State. Phys. Ther. 86, 646-655 (2006).

21. Yesavage, J. A. et al. Development and validation of a geriatric depression screening scale: A preliminary report. J. Psychiatr. Res. 17, 37-49 (1982).

22. Niino, N., Imaizumi, T. \& Kawakami, N. A Japanese translation of the geriatric depression scale. Clin. Gerontol. 10, 85-87 (1991).

23. Stuck, A. E. et al. Risk factors for functional status decline in community-living elderly people: A systematic literature review. Social Science and Medicine vol. 48 445-469 (1999).

24. Hirai, H., Kondo, K., Ojima, T. \& Murata, C. Examination of risk factors for onset of certification of long-term care insurance in community-dwelling older people: AGES project 3-year follow-up study. [Nippon kōshū eisei zasshi] Japanese J. public Heal. 56, 501- 512 (2009).

25. Shinkai, S. et al. Public health approach to preventing frailty in the community and its effect on healthy aging in Japan. Geriatr. Gerontol. Int. 16, 87-97 (2016). 
26. Saito, T., Murata, C., Aida, J. \& Kondo, K. Cohort study on living arrangements of older men and women and risk for basic activities of daily living disability: Findings from the AGES project. BMC Geriatr. 17, 1-14 (2017).

27. Nonaka, K. et al. Is unwilling volunteering protective for functional decline? The interactive effects of volunteer willingness and engagement on health in a 3-year longitudinal study of Japanese older adults. Geriatr. Gerontol. Int. 19, 673-678 (2019).

\section{Figures}




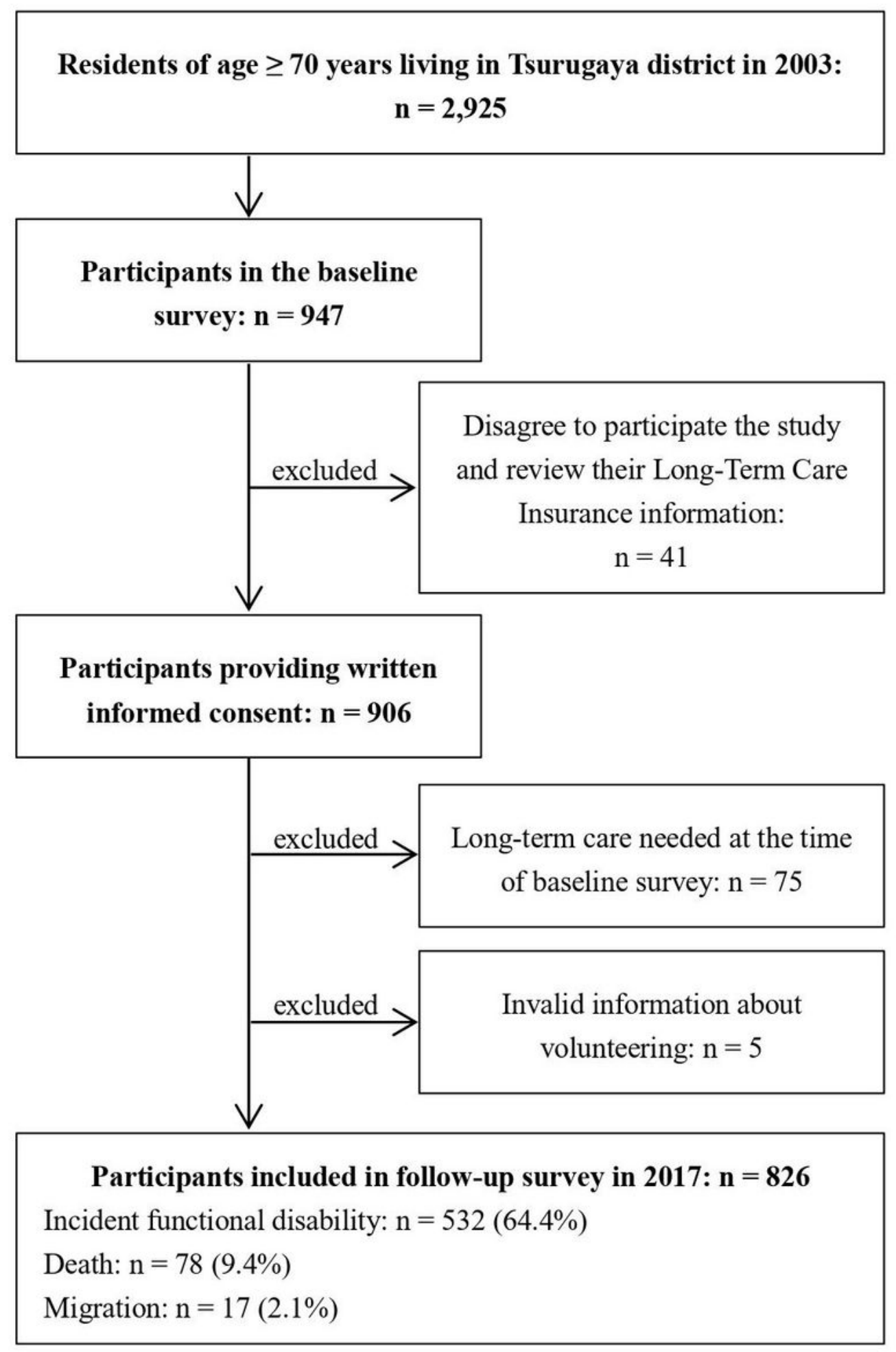

Figure 1

Flow diagram of participant enrollment. 
Number of participants
The risk of incident functional disability for current volunteers

Total, n $\begin{gathered}\text { Current volunteers, } \\ \mathrm{n}(\%)\end{gathered} \quad$ HR $\quad(95 \% \mathrm{CI})^{\dagger} \quad P$ value

\begin{tabular}{|c|c|c|c|c|c|}
\hline \multicolumn{6}{|l|}{ Sex } \\
\hline Men & 395 & 47 (11.9) & 0.90 & $(0.59-1.37)$ & 0.63 \\
\hline Women & 431 & $32(7.4)$ & 0.50 & $(0.29-0.86)$ & 0.012 \\
\hline \multicolumn{6}{|l|}{ Age } \\
\hline$<75$ years old & 443 & $48(10.8)$ & 0.92 & $(0.58-1.46)$ & 0.73 \\
\hline$\geq 75$ years old & 383 & $31(8.1)$ & 0.56 & $(0.35-0.88)$ & 0.012 \\
\hline \multicolumn{6}{|l|}{ Medical History } \\
\hline Absence & 289 & 33 (11.4) & 1.02 & $(0.61-1.71)$ & 0.94 \\
\hline Presence & 537 & $46(8.6)$ & 0.57 & $(0.37-0.87)$ & 0.009 \\
\hline \multicolumn{6}{|l|}{ Marital Status } \\
\hline Married & 558 & $57(10.2)$ & 0.89 & $(0.61-1.29)$ & 0.53 \\
\hline Unmarried & 267 & $22(8.2)$ & 0.40 & $(0.20-0.78)$ & 0.007 \\
\hline \multicolumn{6}{|l|}{ Educational Level } \\
\hline Higher & 533 & $55(10.3)$ & 0.63 & $(0.42-0.94)$ & 0.022 \\
\hline Lower & 275 & $19(6.9)$ & 0.90 & $(0.49-1.65)$ & 0.74 \\
\hline
\end{tabular}

Figure 2

Association between volunteering and incident functional disability by gender, age, history of disease, marital status, and educational level. HR, Hazard Ratio; Cl, Confidence Interval. † Adjusted for age, sex, marital status (living with spouse, living without spouse, missing), education level (age upon graduation from last school $\leq 17,18-21, \geq 22$ years, missing), occupational status (employed, not employed, missing), medical history (stroke, myocardial infarction, cancer, diabetes, bronchial asthma, cataract, glaucoma, arthritis), physical pain (moderate to severe, very mild to mild, none, missing), Timed up and go test (in s (men): $\leq 8.01,8.02-9.29, \geq 9.30$, missing; in s (women): $\leq 8.41,8.42-10.1, \geq 10.2$, missing), depressive symptoms ( $\leq 10,11 \geq$ Geriatric Depression Scale (GDS) score, missing), social support (presence, absence, missing), hobby activity status (none, any, missing). 